having been provided, there is now room for about 550 undergraduates; at present there are 19 academic staff, 33 technical staff and 30 postgraduates. In its research activities the department, headed by Professor G. K. T. Conn, attempts to maintain a balance between the two approaches of solid state physics and upper atmosphere physies. Experiments in the latter are planned and evaluated in the building, but experimental observations are carried out at the Norman Lockyer Observatory at Sidmouth.

\section{Fit to Drive?}

If the present rate of motor accidents in Britain is maintained, more than half the children now born will be injured in road accidents during their lives, and one in fifty will be killed. These figures are disturbingly high, and it seems that medical conditions in drivers such as diabetes, epilepsy, defective eyesight and cardiac conditions are responsible for not more than one per cent of road accidents. This week the Medical Commission on Accident Prevention-formed in 1964 as a result of a request by HRH The Duke of Edinburgh-has published a report setting out the conditions likely to affect the safety of driving, and suggesting advice that can be given to patients suffering from these conditions. Medical Aspects of Fitness to Drive Vehicles (price 5s.) is the first of a series of reports published in the Accident Prevention Series.

Driving under the influence of drugs is one of the six offences for which a driver is automatically disqualified for a year. The effects of drugs on driving are, however, not easy to assess, because other factors such as fatigue, physical and mental disease, and variations between individuals have to be considered. There is also the question of overdoses and side-effects; for example, large doses of dexamphetamine ('Dexadrine') can result in abnormal behaviour which increases the accident risk to the driver and public, while small doses-if taken by a driver who is fatigued-can prevent him from falling asleep at the wheel.

In Britain, any person suffering from epileptic fits is prohibited from driving. As there are about 130,000 adult epileptics who are potential drivers, however, it is not surprising to find that some $15,000-20,000$ epileptic individuals in this country do in fact drive. As the report points out, it is extremely difficult to estimate how many accidents are caused by epilepsy, although in 1967 Dr I. G. Norman found that of 44 accidents resulting from loss of consciousness 12 were associated with epilepsy. It has been suggested that the law should be relaxed so that driving licences can be granted to those epileptics who suffer attacks only during sleep, but so far there has been no official change in the present regulations.

Among other conditions mentioned in the report, patients who suffer from various serious heart complaints are advised not to drive, and drivers of heavy goods vehicles and public service vehicles, the report suggests, should be subject to stricter regulations on heart disease. Functions and mechanisms governed by the central nervous system are numerous and include vision, hearing and the control of movement. A satisfactory standard of visual acuity is, of course, essential for drivers, but the importance of hearing is less clearly defined. Neither is there a case for barring all drivers above a certain age, as the rate of physical and mental decline varies greatly from one person to another. The report does suggest, however, that elderly people should be encouraged to seek medical advice annually from the age of seventy on their fitness to continue driving.

\section{Physicist turns Curator}

THE National Museum of Wales appears to have broken with convention by appointing Professor G. O. Jones, professor of physics at Queen Mary College, London, as its new director. Professor Jones takes over on December 1 from the retiring director, Dr Dilwyn John, who has built up a museum distinguished in many ways but notably for its art collection and schools service. A professor of physics may at first seem a slightly idiosyncratic choice for a director of a national museum, but Professor Jones is no ordinary professor of physics. He has published three novels - not science fiction-in the past ten years, is an amateur musician, and has organized an unusual art gallery at the physics department of Queen Mary College where young painters are invited to put on one-man exhibitions which change

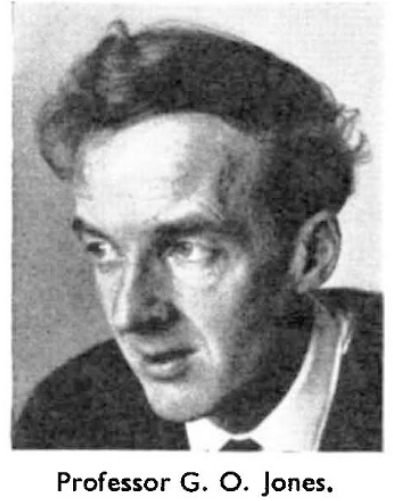

about every six weeks. This must be unique in Britain although there is a similar enterprise in Moscow. As a young physicist, Professor Jones worked at Oxford during the war on the Tube Alloys project, the British contribution to the atomic bomb. In 1949 he moved to Queen Mary College as reader, where he has established low temperature physics research.

From all this one can only guess that the increasing burdens of administration in London and his continuing interests in the arts have prompted Professor Jones to make the clean break with physics and move to the museum. It would be true to character if the theme of his policy at the Welsh National Museum, which comprises the main museum of Cardiff, the Welsh Folk Museum at St Fagans and two much smaller institutions, turns out to be making the museum a real centre for the Welsh community. That, of course, is the slogan of many museums nowadays and is clearly far easier said than done. But demography, at least, is on his side. About half the population of Wales lives within fifty miles of Cardiff and the museums.

Professor Jones makes no secret of the fact that he would rather have the winning poems of the Eisteddfod publicly read at the museum than to have cases displaying bardic regalia. Given his close associations with writers, scientists and musicians, to say nothing of the resurgence of Welsh nationalism, it should be no surprise to anyone if the National Museum becomes the scene of some lively teach-ins, lectures and concerts. For- 